\title{
Solo Analysis of Efl Curricula in Turkey
}

\author{
Reyhan Ağçam,
}

Pınar Babanoğlu,

Kahramanmaraş Sütçü İmam University

\section{Abstract}

Curriculum simply refers to the means and materials with which students will interact for the purpose of achieving identified educational outcomes (Ebert et al., 2013). In Turkey, the curricula for a variety of courses to be taught in primary and secondary state schools are designed by the Ministry of National Education (MoNE), and they are subject to change at uncertain periods. The current research aims to investigate curricula for English as a foreign language course for $5^{\text {th }}, 6^{\text {th }}$ and $7^{\text {th }}$ grades that have been recently introduced by MoNE (2017). It exclusively compares them through an analysis of learning outcomes identified in each based on the Structure of the Observed Learning Outcome (SOLO) taxonomy developed by John Biggs and Kevin Collis (1982). Accordingly, document analysis method was used to analyze learning outcomes identified in the abovementioned curricula into four levels of the SOLO taxonomy: (i) uni-structural, (ii) multi-structural, (iii) relational, and (iv) extended abstract. The study will report findings obtained from the analysis and practical implications on the curriculum design of EFL courses taught in various grades, and conclude with a few suggestions for further directions.

Keywords: EFL curriculum, SOLO taxonomy, learning outcome 